\title{
Features and Causes of Oromo and Somali Conflicts: The Case of Miesso District of Oromia and Mullu District of Somali Regional States, Ethiopia
}

\author{
Abdurahman Ousman Dansa ${ }^{1, *}$, Abadir Youya Musa ${ }^{2}$ \\ ${ }^{1}$ College of Social Science and Humanities, Climate Change and Disaster Risk Management Program, West Hararghe High Court, Ethiopia \\ ${ }^{2}$ College of Social Science and Humanities, Peace and Development Studies Program, Haramaya University, Haramaya, East Ethiopia
}

Email address:

adansa59@gmail.com (A. O. Dansa),abadiryuya4@gmail.com (A. Y. Musa)

${ }^{*}$ Corresponding author

\section{To cite this article:}

Abdurahman Ousman Dansa, Abadir Youya Musa. Features and Causes of Oromo and Somali Conflicts: The Case of Miesso District of Oromia and Mullu District of Somali Regional States, Ethiopia. Humanities and Social Sciences. Vol. 9, No. 5, 2021, pp. 165-180. doi: $10.11648 /$ j.hss.20210905.15

Received: September 5, 2021; Accepted: September 24, 2021; Published: September 29, 2021

\begin{abstract}
This article aimed to investigate features and causes of the conflicts between Oromo and Somali Pastoral and agro-pastoral (PAP) groups in the study area. Hence, 160 PAP households were randomly selected to facilitate primary data collection by using household survey. Qualitative data were collected by using key informant interviewees (KIIs) and Focal group discussions (FGDs). Field observation, informal discussion and review of secondary data were also supported data collection process of the study. Descriptive research design; descriptive and inferential statistics were employed. The proportion of sample households composed of $49 \%$ Oromo and 51\% Somali groups. The result of findings showed recurrent drought, rangeland degradation, conflicting land use between the contending groups, hostile relationships, enmity stereotype and incitement, instability due to increasing frequency and magnitude of violent conflicts, firearms and weapons proliferation and weak capacity of customary institutions were ranked as the main features of conflicts in the study area. High frequency of prevalence violent conflicts was seen in the past two decades (2000-2020) with increasing trends of conflicts, as $83 \%$ of households responded. The Scarcity of range resources, lack of property rights to communal grazing resource, weak capacity of customary institutions and government system to ensure rule of law were found the main causes that often prompt contending groups towards violent conflicts, significant differences, at $\mathrm{p}<0.01,0.05$ and 0.1 , between the two groups. In the light of findings this paper concludes that the two PAP groups are significantly different in all factors that prompt contending groups to embark on conflicts due to their differences in socio-economic, cultural, political and resource-related factors.
\end{abstract}

Keywords: Causes, Conflict, Ethnic Group, Oromo and Somali

\section{Introduction}

\subsection{Background of the Study}

In Africa, scarcity driven resource conflicts are often seen as an outcomes of intense competition on natural resources in the context of environmental stress [1]. Such conflicts have continually weakened and reduced countries' capacity to achieve their development agenda. Those occurring at microlevel on specific resources prevent many countries from undergoing rapid social and economic change [2]. Empirical literature showed there are no specific causes of conflict, because it arises for different reasons and there are different types of conflicts in human society [3]. Hence, the causes of conflict are numerous and complex, creating problem of analysis of specific conflict situations.

Apparently, inter-group conflicts in pastoral and agropastoral (PAP) regions of eastern Africa have increasingly become the defining features since few decades [4]. In this regard, pastoral frontiers of eastern and southern Ethiopia and Kenya are typical examples where conflict has become recurrent with a convergence of complex and multi-layered actors and causes related to socio-economic interests and an increasing competition over natural resource [5]. People in 
these areas have experienced recurrent and protracted conflicts that resulted in breakdown of law and order, disastrous displacement of peoples, destruction of properties, humanitarian crises and socio-economic shocks [6].

The recurrence inter-groups conflicts between Oromo and Somali PAP groups in Miesso/Mullu area of West Hararghe Zone of Oromia and Sitti Zone of Somali Regional States, the study area, is one of well-documented violent conflicts in eastern Ethiopia [7]. In this area, the stock of natural resources (grazing lands and water) are shrinking from time to time due to the impacts of drought, land degradation and changes in land use between crop cultivation and livestock production relying on communal grazing lands. To this effect, one can see that there is no doubt that the factors mentioned intensify resource scarcity and competition over range resources that lead to violent conflicts.

A number of empirical studies were conducted on aspects of inter-group conflicts between PAP groups in eastern Ethiopia, the studies mainly focused on the causes and impacts of conflicts in generic manner [8]. They assessed the underlying factors behind the formation, development and transformation of inter-group conflicts [7]. Other studies revealed that the prime causes of inter-group conflicts in PAP areas of eastern Ethiopia centered on competition over grazing land and water resources [9]. Bamlak [10] also reported territorial expansion, livestock raids and counter raids, ethnic rivalries and revenge attack for past hurt as the main causes of recurring conflicts between PAP groups in the area. Inter-group conflicts were also instigated by lack of political representation, absence of good governance, historical animosities and increased reduction in household income, unfair resources distribution and volatile regional boundaries [11]. Nonetheless, earlier studies have methodological dearth in pinpointing conflict of interests between range resources users, the core causes and its features in Miesso/Mullu pastoral and agro-pastoral area. Therefore, it needs to bridge existing information and knowledge gap in this regard, if it is sought to reduce tensions and violent conflicts in the study area.

\subsection{Statement of the Problem}

Conflicts between Oromo and Somali PAP groups have existed in different forms for centuries, and are not new phenomena. Centuries of interactions between the two groups have created a complex pattern of ethnic and linguistic relationships [12, 9]. Oromo and Somali groups share common grazing resources in Miesso/Mullu area [13]. The primary resource users in Miesso/Mullu study area are Oromo and Somali ethnic groups. The Oromo groups are mostly agro-pastoralists, while the Somali groups are pastoralists [7]. However, PAP livelihoods are characterized by risk and uncertainty due to fluctuating environment and occasional shocks [4].

Traditionally, the vagaries of natural environment were overcome through access to and management of communal rangelands, mobility of stock and institutions of mutual assistance that based on the principles of flexibility, complementarily, multi-functionality, reciprocity and sustainable communal resource management [14]. However, high stock mortality during droughts is often seen as a symptom of inherent flaws in livestock production systems; barren rangelands are taken as evidence of unsustainable grazing pressure and increasing land degradation [15].

Since recent decades with the challenges of human and livestock population pressure and shrinkage of rangeland resources, pastoralists are observing significant decline in the availability and quality of key range resources that form foundation to (agro) pastoralists' livelihoods [16]. As a result, while PAP groups compete to maximize their share of the limited grazing and water resources, the struggle inevitably leads to violent conflicts [7]. Even after 2015, the conflicts involved more actors beyond the local community members including armed forces, local militias and Special Forces of Oromia and Somali regional states [13]. For instance, the 2018 violent armed conflicts between the two groups caused massive displacement [2].

To this end, understanding and identification of the conflict context and existing conflict of interests between resources user groups is critical for designing/scaling up of an effective intervention for conflict prevention. However, these informations are not been explored, well-understood and documented regarding to specific study area. Therefore, from this ground that the need to investigate the core causes and features of Oromo-Somali violent conflicts seen as a thoughtful gap that this study tried to bridge in Miesso/Mullu study area by addressing the following objectives.

\subsection{Objective of the Study}

General objective: to investigate the features and causes of Oromo-Somali conflicts in the Miesso/Mullu Districts of West Hararghe Zone of Oromia and Sitti Zone of Somali Regional States, respectively.

Specific objectives of this study were:

1) To analyze frequency, characteristic and trends of Oromo-Somali conflicts in study area;

2) To explore the causes of Oromo-Somali conflicts in the Miesso/Mullu area.

\section{Research Methodology}

\subsection{Description of Study Area}

\subsubsection{Location and Area}

Miesso and Mullu districts, the study area, are neighboring districts located in West Hararghe Zone of Oromia, and Sitti Zone of Somali Regional States. Geographically, Miesso and Mullu districts are located between $8^{\circ} 29^{\prime \prime} 41^{\prime} \mathrm{N}$ and

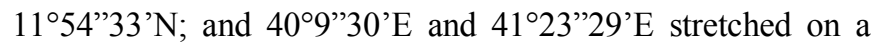
land area of 2,821 square kilometers. Miesso and Mullu are the capital towns of the two districts situated in the east at a distance of $290 \mathrm{~km}$ and $323 \mathrm{~km}$ from Addis Ababa along the main Addis-Harar/Dire Dawa asphalted highway as well as the historic and the recently built Ethio-Djibouti railways. Miesso district shares boundaries with Doba, Chiro and GumbiBordodde districts of West Hararghe Zone in the east, south 
and west, respectively. Miesso district also bordered with Mullu and Afdem districts of Sitti Zone of Somali National
Regional state in the north, north east and east in that order. Figure 1 below illustrates the location map of the study area.

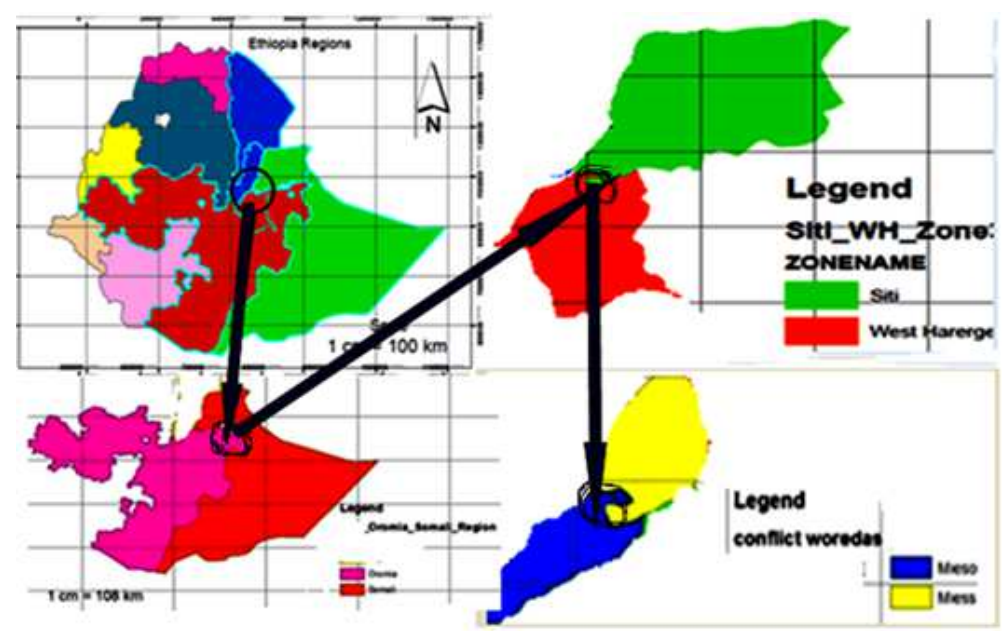

Figure 1. Location Map of the Study Area Source: Ethio-GIS, 2021.

\subsubsection{Relief and Soil}

Miesso/Mullu districts are surrounded by a chain of mountains in nearly all directions. The altitude of the study area is ranging from $760 \mathrm{~m}-2500 \mathrm{~m}$ above mean sea level. The major soil types are sand and clay. The major soils classification include Vertic Cambi soil (Orthic and Ferralic), Haplic Luvisol (Orthic) and Eutric Cambisol (Orthic), accounting for $50 \%, 16 \%$ and $11 \%$, respectively [17].

\subsubsection{Climate and Drainage}

Based on the digital data, the mean annual temperature of Miesso/Mullu districts is around $23^{\circ} \mathrm{C}$, while average annual rainfall is between 635 and $945 \mathrm{~mm}$, with an average of about $790 \mathrm{~mm}$ [18]; while average annual rainfall is about $690 \mathrm{~mm}$ and lies between the ranges of $471 \mathrm{~mm}$ and $1145 \mathrm{~mm}$. Figures 2 and 3 below illustrate mean temperature and rainfall distributions in the last 20 years (1999-2018) respectively.

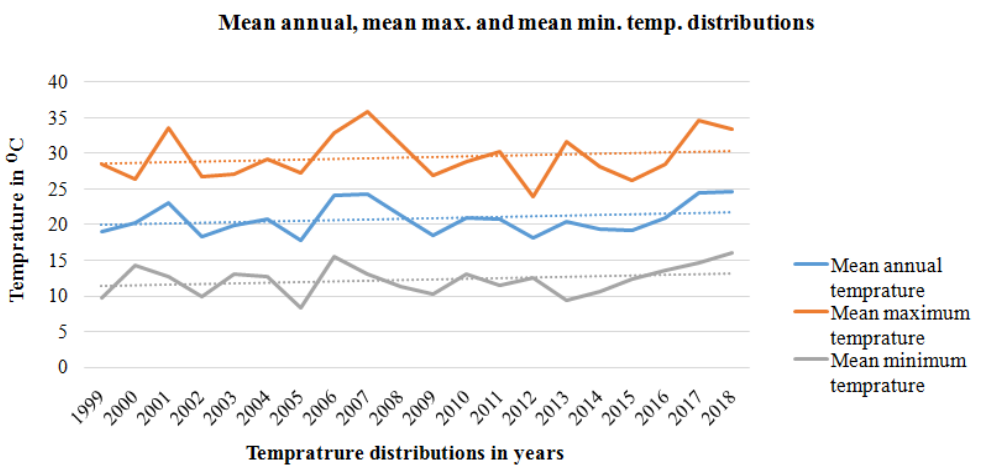

Figure 2. Temperature distributions in the last two decades (1999-2018); Source: NMA, 2019

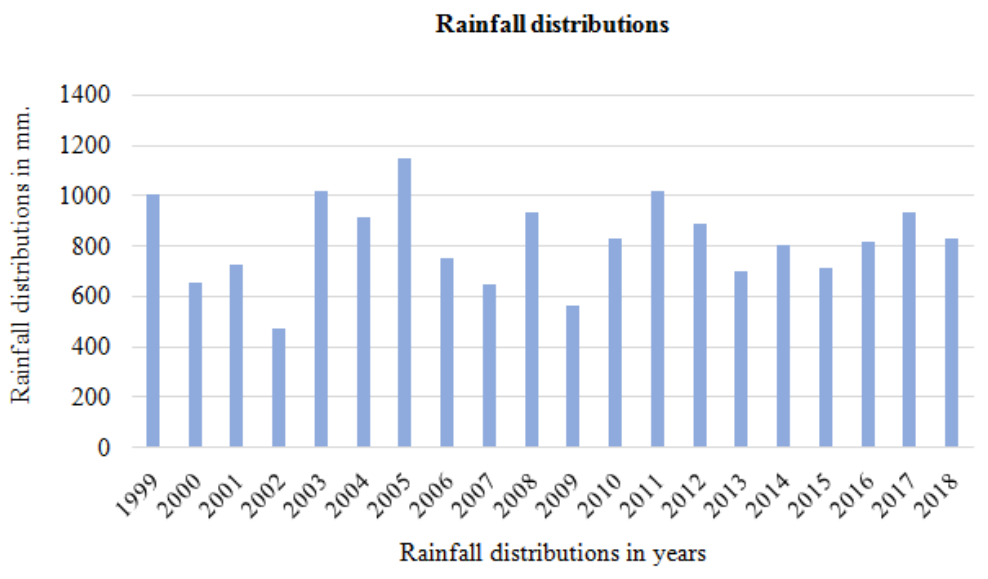

Figure 3. Rainfall distribution in the last two decades (1999-2018); Source: NMA, 2019. 
On the other hand, based on the traditional classification of climate system, Miesso/Mullu districts are classified under Kola (semi-arid and arid) climatic zone. The bimodal nature of rainfall regime in the district has two rainy seasons. The short rain falls during the months of March and April and the longer summer rainy season runs from July to September. Farm households have reliance on the longer summer rainy period. The shorter rainfall also enhances water availability for livestock and household consumption. The drainage pattern of the districts encompasses three intermittent river systems; namely, Yabdo River, Miesso River and Bacheysa River that only drain during the rainy season with little contribution to irrigation during dry periods. The drainage system in the district is a part of the Awash basin [18].

\subsubsection{Vegetation and Wildlife}

Miesso/Mullu districts are endowed with abundant natural resources and it has command of massive rangelands where agro-pastoralists and large number of livestock rely on during drought periods [18]. Hilly areas are under wooded grassland or bush grassland; flat land is under rain fed crops. Extensive grazing system is the major land use in the area. Cattle, goats, sheep, camels and donkeys are the major stock. Trees include: Boswellia papyrifera, Acacia seyal, Acacia senegal, Acacia nilotica, Ziziphus, Diospyros mespiliformis, and Balanites aegyptiaca are the dominant bush species [19]. The two districts are also home to diverse wild life, which Traqelaphus scriplus, Phacochoerus africanus, Theropithecus gelada, Grivel monkey, Oryx besisa, Oryctolagus cuniculus, Geochelona sulcata, Colobus quereza and Equus quaqqaa are the major ones [17].

\subsubsection{Population Characteristics}

Based on information obtained from the Miesso district's office of economic development planning [20], 203,432 ( $51 \%$ females) human population is estimated to live in the two districts with density of 72 people/square kilometers. Of total population, about $14 \%$ or 30,515 (49\% males) are urban dwellers residing in small towns of Miesso and Mullu.

\subsection{Research Design}

Research design is the blue print for fulfilling research objectives and answering research questions [21]. Besides, it is a master plan specifying the methods and procedures for collecting and analyzing the needed information. It ensures that the study will be relevant to the problem that it uses economical procedures. The same authors discuss three types of research designs, namely exploratory (emphasizes discovery of ideas and insights), descriptive (concerned with determining the frequency with which an event occurs or relationship between variables) and explanatory (concerned with determining the cause and effect relationships).

Thus, in this study the descriptive and explanatory research designs were used based on the purpose for which it can serve to fulfill the objectives of the study. Cohen (1994) and Grey [22] also suggested the descriptive type survey research has the advantages in that it employs large amount of data from relatively wider area and allows high degree of interaction with respondents. It can easily be adapted to collect general information, provides relatively simple and straight forward approach to study attitude, values, and beliefs, and can also help to measure particular phenomena at a fixed point in time. Thus, the survey method helps to obtain firsthand information and enables to have access to multiple methods of data collection.

This study tried to highlights the study area, demographic and socio-economic characteristics of sample households in the study area. Besides, the study also described the frequency of conflict prevalence and trends of violent conflicts between Oromo and Somali PAP groups. On the other hand, the study explained the features and causes of Oromo-Somali violent conflicts in the study area. Furthermore, as Kothari, C. [23] stated mixing qualitative and quantitative approaches gives the potential to cover each method's weaknesses with strengths from the other method. Accordingly, both quantitative and qualitative data were collected concurrently by using combinations. Creswell [24] recommends that combination of methods for data collection and data analysis help to confirm, triangulate and substantiate the results of analysis and findings of the study.

\subsection{Sampling Procedures}

In this study, a multi-stage sampling strategy was followed to select sample districts, kebeles and sample household heads. In the first stage, Miesso and Mullu districts are purposely selected for this study, because of its conflict hot spots area with increasing frequency and prevalence of Oromo-Somali violent conflicts. In the second stage, six kebeles (three from each district) were purposefully selected from the list of 31 and 24 kebeles in the two districts, respectively.

The selection process of sample kebeles was based on documents review; field visit and discussions held with most important selected societal groups namely; local leaders, clan leaders, DAs, heads and experts of the two districts offices of peace and administration, security and law enforcement, pastoralist areas development and disaster risk management.

The sampling procedure also followed some parameters for the purpose of selection such as; farming system, level of land degradation, vulnerability to recurrent conflict, frequency and severity of conflict, and security issues and impacts of conflict on those venerable groups that makes inclusion of woman headed household.

To this end, an agreement was reached that homogeneity existed in agro-ecology, semi-arid and arid ecology holds the same for the two specified districts; likewise, pastoralist production system (animal herding) is the dominant farming system in Mullu district kebeles; while agro-pastoralist system covers for the majority of Miesso district. Thus, Mullu, Somedayo and Kulmiye kebeles were selected from Mullu district of Somali Regional State, whereas, Kurfasawa, Fayo and Kikiliftu kebeles were selected from Miesso 
district of Oromia Regional State. Finally, six sample kebeles were selected for the study.

\subsection{Sample Size}

James P. Sampson, [25] suggested that a target population is well-defined set of people, service, elements, events, groups or households that are required to investigate. A target population should have some observable characteristics about which the researcher intends to generalize the results of the study. Sample size from the target population is also necessarily determined for household survey of this study. Sample size determination is also required to have a demarcation of the boundary in which the survey is undertaken reasonably with available time, resources and researcher's knowledge of the study area. To decide the sample size of the target population, the sampling frame of member household heads in each sample kebeles was used. Thus, for this study, sample size was determined based on the formula recommended by Kothari [23] for a finite population;

$$
\mathrm{n}=\frac{z^{2} \cdot p \cdot q \cdot N}{E^{2}(n-1)+z^{2} \cdot p \cdot q}
$$

Where, N: the population size; n: sample size; $\mathrm{p}$ : the sample proportion, $0.5,(\mathrm{q}=1-\mathrm{p})$;

Z: the standard deviation at $95 \%$ C.I. $(\alpha=1.96)$; and, e: acceptable error (precision); 0.075;

Given: $\mathrm{N}=1874$;

Required: $\mathrm{n}=$ ?

Soln: $\mathrm{n}=(\mathrm{Z})^{2} * \mathrm{p} * \mathrm{q} * \mathrm{~N} /(\mathrm{e})^{2}(\mathrm{~N}-1)+(\mathrm{Z})^{2} * \mathrm{p} * \mathrm{q}$

$\mathrm{n}=3.84 * 0.5 * 0.5 * 1874 / 0.0056(1873)+3.84 * 0.5 * 0.5$

$\mathrm{n}=156$

Thus, the result, $\mathrm{n}=156$ was the minimum reliable number of sample size or sampling units. To maintain safe and accurate sample size it was adjusted to 160 by considering replacement of at least 4 sample households if missed for some reasons. The unit of analysis for this study is pastoralist/agro pastoralist household head selected for this study from each sample kebele.

\subsection{Sampling Techniques}

In the third stage of sampling procedure, the probability proportion to size (PPS) technique was used to assign the number of sample household heads (the sampling units) in each kebele. Finally, sample households were randomly selected from the sampling frame of household heads in the respective sample kebeles. Table 1 below summarized sample household heads selected for the study.

Table 1. Sample household heads selected for this study.

\begin{tabular}{llllll}
\hline No. & Name of sample kebeles & Dominant Ethnic group & Number of Households & Sample size (number) & Percentage (\%) \\
\hline 1 & Mullu & Somali & 384 & 33 & 21 \\
2 & Somedayo & Somali & 317 & 27 & 17 \\
3 & Kulmiye & Somali & 268 & 23 & 14 \\
4 & Kurfa Sawa & Oromo & 332 & 28 & 17 \\
5 & Kikiliftu & Oromo & 282 & 24 & 15 \\
6. & Fayo & Oromo & 291 & 25 & 16 \\
Total & & 1,874 & 160 & 100 \\
\hline
\end{tabular}

Source: Own survey, 2021.

Moreover, for qualitative data purposive sampling was employed. Thus, total 58 participants of FGDs comprising local leaders, elders, clan leaders (Abba Gadas and Ugazes), religious heads, community representatives (women and youth) and internally displaced peoples (IDPs) were selected in the six sample kebekes and districts level. Considering the advantage of FGDs which help the investigator develop understanding about why people think the way they do [26], the participants of FGDs were selected based on their willingness, sex, rich knowledge and experience, clanship, and participation in conflict resolution efforts since the issues discussed have community concerns. To this end, each group was comprised 8-12 participants of FGDs. The rationale is that the investigator would found and discern individuals with rich knowledge and experience about the issues under investigation. Therefore, the selection of participants for FGDs has been done in consultation with the concerned experts of the study districts. Key informants were also purposely selected for key informants interview (KII) from local leaders, elders, clan leaders (Abba Gadas and Ugazes), office heads, experts and pastoralist areas development agents (DAs) for kebeke and district sessions.

\subsection{Methods of Data Collection}

\subsubsection{Data Types}

In order to make data collection process more comprehensive and fulfill the objectives of this study the type of data required included both primary and secondary in nature, and quantitative and qualitative in scale. Primary quantitative data emphasized on the demographic features and socio-economic characteristics of sample households, basic data on agro-ecological zonations, land use and land cover, data on climate and soil. Primary qualitative data included conflict context, farming system, climate, grazing and water resources for PAP production system, perspectives, views and perceptions towards the features and causes of violent conflicts between Oromo and Somali PAP communities focused on the main actors, frequency of occurrence, trends of conflicts in the study area. 


\subsubsection{Sources of Data}

Primary quantitative and qualitative data were collected from sample household heads during formal survey done in each sample kebele, local leaders, local elders, clan leaders ( $A b b a$ Gadas and Ugazes), religious heads, community representatives (women and youth), DPs, heads and experts and internally displaced peoples (IDPs) and participants on KIIs and FGDs. Secondary data were also collected from records and reports, published and unpublished materials, books, government publications, journals and periodical performance reports accessed from PTCs and district level offices, libraries, study papers retrieved from respective web-sites.

\subsubsection{Instruments of Data Collection}

\section{(i). Questionnaire}

Questionnaires were used for primary data collection from sample respondents through semi-structured interview schedule (SSIS) for the formal survey. The SSIS was constructed with open-ended and closed-ended items. Interview items were carefully selected and constructed based on review of literature and opinions collated from experts, academicians and participants of KIIs carried out in the study area. Reliability and validity tests for data were conducted before actual field administration of the survey instrument. Data were collected from April 2020 - June 2020. A total of 167 questionnaires were used to collect data by trained enumerators including 7 extra questionnaires for replacement, as a result the response rate was $96 \%$ in that it was able to secure 160 filled questionnaires for all sample households.

\section{(ii). Focused Group Discussions (FGDs)}

Qualitative data were generated through using semistructured key informant interviews, focused group discussions, personal observations and informal discussions. Focused groups discussions involved local leaders, local elders, clan leaders (Abba Gadas and Ugazes), religious heads, community representatives of women and youth, PADAs, heads and experts and internally displaced peoples (IDPs). FGDs helped explore insight, perceptions, experiences, and understanding a group of people who have experience in common with regard to a situation [27].

Data's collected through individual household survey were cross-referred during FGDs. FGDs also helped to crosscheck data collected from secondary sources. Total of 61 participants of PAP households were involved in seven (7) FGDs conducted, each comprised 8-10 members in each focused study kebele and district level discussion. This includes 14 elders (community opinion leaders), 12 local leaders, 6 clan leaders (Ittu, Ala and Nole clans of Oromo and Issa and Hawiyya clans of Somali groups), community representatives of 7 women and 9 youth groups, and 13 development agents guided by a checklist carefully constructed for the same purpose.

\section{(iii). Key Informant Interview (KII)}

Interviews with key informants purposely selected for this study were carried out to collect qualitative data on views, perceptions, attitudes and explanations on the occurrence, history, feature and causes of violent conflicts between Oromo and Somali PAP group's actors, frequency of occurrence and trends of conflicts in the study area. KIIs involved local leaders, elders, clan leaders (Abba Gadas and Ugazes), office heads, experts and development agents and concerned internally displaced peoples (IDPs).

This method helped to corroborate data collected through other methods like secondary data review, household survey and field observations. Checklist was carefully constructed and adopted to guide KIIs. Total of 52 key informants were involved. Each session comprises minimum of 7 and maximum of 12 key informants, total of eight (8) KIIs in each of the six study kebeles and district level discussions.

\section{(iv). Field Observation}

The objective of field observation by the researcher was to create self-acquaintance with Oromo and Somali community members, study environment and related aspects deemed necessary in the course of undertaking study. The field observation helped the investigator to create a mental picture of the local context and understand the facts, phenomena, frequencies of events, cause and effects relationships between study variables and/or attributes, and ultimately the impacts on the society, economy and environment.

Besides, the instrument helped the researcher to look into existing opportunities that can be envisaged to improve the current state of challenges. A checklist was used to guide the field observation. Frequent field visits and observations were carried out throughout the study period (January, 2020 March, 2020).

\subsection{Reliability and Validity}

\subsubsection{Reliability Test}

Reliability is concerned with the extent to which a measure is consistent and stable in measuring what it is intended to measure; while validity is concerned with the accumulation of evidence about the extent to which an instrument or test actually measures what it is intended to measure [25]. In this study, a reliability test for internal consistency of study instruments was administered following the construction of selected items, checking for detection of deficiencies and comments and feedback from the supervisors. Thus, it was managed to contact experts from WHZASO, WHZJO and Miesso/Mullu districts level offices and academicians from Oda Bultum University with immediate relevance to the topic of the study. Accordingly, the investigator became able to invite 18 people and convene in West Hararghe Zone Peace and Administration Office meeting hall to evaluate the study instrument.

Thus, total of 54 items, 36 for SSIS and 18 for the checklists were distributed to participants to test each item on a five-point Likert scale as: 5 for "strongly agree, 4 for "agree", 3 for "undecided", 2 for "disagree" and 1 for "strongly disagree." The test scores were collected and fed to SPSS Ver. 23.0 programme for Cronbach's alpha test. 
Cronbach's alpha is a convenient test used to estimate the reliability or internal consistency of a composite score for survey instrument. It involved the Pearson Product Moment Correlation analysis [22]. The result of analysis indicated that, Cronbach's alpha coefficient was found to be 0.791 . George and Mallery [25] provide the following rules of thumb to interpret values as: Cronbach's alpha of: " $>.9-$ Excellent, $>.8$ - Good, $>.7$ - Acceptable, > .6 Questionable; $>.5$ - Poor, and $<.5$ - Unacceptable." As a result, instruments were found consistent with the objectives of the study and research questions; finally, it was made possible to head for actual data collection procedure.

\subsubsection{Validity Test}

Validity refers to the extent an instrument or scale tests or measures what it intends to measure. This means validity is the extent to which differences found with a measuring instrument reflect true differences among those being tested. Validity is concerned with the accumulation of evidence about the extent to which a study instrument actually measures what it is intended to measure [23]. In this study, a pilot test for both interview schedules and checklist was done before actual administration. Thus, question items were subjected to pre-testing on a small group of 19 (10 sample and 9 non-sample) PAP households in two sample kebeles.

The purpose of the pilot test was to assess ease of comprehension, relevance, effectiveness in conveying useful information, and to what extent the questions are interpreted and understood by different individuals. This procedure was conducted by 9 enumerators (4 experts and 5 DAs) familiar with the community groups. Thus, reconstruction and modifications were made based on the feedback and suggestions obtained from the participants involved. The validity test procedure helped ensure effectiveness of the items in capturing the proper information. This resulted in the final step where the English version was translated to Afan Oromo and Afan Somali to fit to the local languages and proceed towards actual data collection.

\subsection{Method of Data Analysis}

As usual, the collected data were analyzed by using different analytical techniques after coding and entry into computer programme of statistical packages. Qualitative data generated from household survey, FGDs, KIIs, field observation and secondary sources were analyzed by using tabulation, triangulation, description and interpretation, perceptions and explanations of themes under question based on the objectives of the study. Both descriptive and inferential statistics were adopted to facilitate processes of data analysis and interpretations of the results. Secondary data were also incorporated to augment the result of analysis for primary data in each step as required. The following sections briefly discuss the statistical and analytical tools used.

\subsubsection{Descriptive Statistics}

In this study, descriptive statistics was used to reduce quantitative data collected into summary formats by tabulation in order to facilitate for comparisons between groups or variables involved in the study. Descriptive statistics was used for quantitative data analysis on the biophysical and socio-economic characteristics of sample household heads. Such descriptive statistics included frequency, means, standard deviation, range, percentages, pie-chart, figures, graphs and tables.

\subsubsection{Inferential Statistics}

Inferential statistics allows inferring from data through analysis the relationships between two or more variables, and how several independent variables might explain the variance in a dependent variable.

\section{(i). Chi-square Test}

The Chi-square test of independence or the Pearson Chisquare test is one of the most useful statistics to analyze group differences when the dependent variable is measured at a nominal level. The Chi-square test has also advantages including its robustness with respect to distribution of the data, its ease of computation, detailed information that can be derived from the test, its use in studies for which parametric assumptions cannot be met, and its flexibility in handling data from both two group and multiple group studies [28]. In this study, chi-square test is used to explain that among groups of sample respondents with identical responses, there exists significance difference in opinions the majorities' suggested that might substantiate the need to consideration for measures to be recommended.

\section{(ii). One-Sample T-test}

The One - sample T-Test is applied to measure the difference between sample mean tabulated by descriptive statistics for scores of mean and standard deviation for each of indicator variable on five-point Likert scale. By using One-sample Test statistics, sample mean is compared with test value of 3 , (average for " 15 ," the maximum point of fivepoints Likert scale; which, 5 for "strongly agree", 4 for "agree", 3 for "undecided" or "no idea", 2 for "disagree" and 1 for "strongly disagree"), then it will indicate whether there is a significant difference between the sample mean and the test value. Low p-value $(<0.05)$ indicates high significant difference between sample mean and test value.

\section{(iii). Correlation Coefficient}

In addition, correlation coefficient is applied to test the internal consistency and reliability of the properties of measurement scales that compose the composite score for survey instrument; i.e., Cronbach's alpha tests [22].

\subsection{Ethical Considerations}

Research ethics is the moral principle guiding research (Criswell, 2013). The validity of this article was covered by a research permit and authorization. The reviewer observed acceptable etiquette when interacting with all the research respondents. The participants of FGD and KII also assured that the information they provided would be handled 
confidentially and would only be used for academic purposes. Permission was sought from the respondents in order to record their voice and verbatim captions in this thesis. Then, the reviewer was collected data after forward proper information to the target groups and the purpose for which he was collected data.

\section{Results and Discussions}

\subsection{Features, Frequency and Trends of Oromo-Somali Inter-group Conflicts}

Asebe [4] reported inter-group conflicts in PAP areas of eastern Ethiopia have increasingly become the defining features of the region with the consequential effects of humanitarian, economic, security and political challenges to the states and local communities. In this regard, this study tried to look into the features of violent conflicts recurrently burst between Oromo-Somali groups. In addition, the frequency of prevalence and trends of Oromo-Somali conflicts were also discussed in brief and the findings are presented under the following sub-sections.

\subsubsection{Main Features of Oromo-Somali Inter-group Conflicts}

In this study, sample respondents were asked to disclose the degree of agreement/disagreement towards the key features of Oromo-Somali inter-group conflicts on a fivepoint Likert scale from a list of items carefully constructed based on suggestions of PAP households in Mi'esso/Mullu area and related literature.

Quite majority of sample households summarized the features of conflict environment in ten indicator variables having significant difference between responses of the groups (table 2 below). This implies that the attitude of sample households towards each indictor variable for main features manifesting violent conflicts in the study area exhibited differences between the two groups due to diversity in socioeconomic, political and resource attributes.

Table 2. Major features of Oromo-Somali inter-group conflicts $(N=160)$.

\begin{tabular}{|c|c|c|c|c|c|c|c|c|}
\hline \multirow{2}{*}{ No. } & \multirow{2}{*}{ Description of features of the conflict environment } & \multirow{2}{*}{ Mean } & \multirow{2}{*}{$\begin{array}{l}\text { Std. } \\
\text { Dvn }\end{array}$} & \multirow{2}{*}{ t-value } & \multirow{2}{*}{ Sign. } & \multirow{2}{*}{$\begin{array}{l}\text { Mean } \\
\text { diffce }\end{array}$} & \multicolumn{2}{|c|}{$95 \% \mathrm{CI}$ of the difference } \\
\hline & & & & & & & Lower bound. & Upper bound. \\
\hline 1. & Recurrent drought; & 4.81 & .29 & $39.6 * *$ & .032 & 1.81 & 1.64 & 1.99 \\
\hline 2. & Bush encroachment; & 4.75 & .03 & $22.1 *$ & .081 & 1.75 & 1.62 & 1.94 \\
\hline 3. & $\begin{array}{l}\text { Conflicting land use between agro-pastoralists (Oromo) and } \\
\text { pastoralists (Somalis); }\end{array}$ & 4.71 & .57 & $45.9 * * *$ & .002 & 1.71 & 1.53 & 1.88 \\
\hline 4. & Historically hostile relationships; & 4.63 & .40 & $38.0 * *$ & .040 & 1.63 & 1.39 & 1.76 \\
\hline 5. & Increasing frequency and magnitude in inter-group conflicts; & 4.58 & .56 & $55.7 * * *$ & .006 & 1.58 & 1.42 & 1.91 \\
\hline 6. & Volatile regional boundary demarcation; & 4.54 & 1.06 & $28.5 * * *$ & .000 & 1.54 & 1.26 & 1.83 \\
\hline 7. & More actors involvement in conflicts beyond local community; & 4.39 & 0.76 & $33.5^{* *}$ & .038 & 1.39 & 1.18 & 1.74 \\
\hline 8. & Free movement of weapons proliferation; & 3.98 & .72 & $56.5^{* * *}$ & .007 & 0.98 & 0.66 & 1.24 \\
\hline 9. & Massive internal displacement; & 3.76 & 1.03 & $19.3 *$ & .081 & 0.76 & 0.56 & 0.99 \\
\hline 10. & Eroded capacity of customary institutions; & 3.67 & .786 & $48.6 * *$ & .040 & 0.67 & 0.84 & 1.26 \\
\hline
\end{tabular}

Source: Own survey, $2021 * * *$ and $* * *$ - Significant at $\mathrm{p}<0.01,0.05$ and 0.1 .

As it is evident from the table the first ranked indicator feature of violent conflicts in the study area is recurrence of severe drought that leads to declining grazing and water resources base, significant at $\mathrm{p}<0.05$. This implies that the prevalence and escalations of tensions and conflicts in the area.

Gezu, G. [29] also reported that recurring drought in PAP areas in eastern Ethiopia has led to a declining grazing resource base that has gradually intensified competition and conflict. The second ranked feature of the conflict environment is increased reduction in availability and quality of key rangeland resources due to bush encroachment, significant at $\mathrm{p}<0.1$, that inhibited access to grazing and water resources during severe droughts. This has worsened the frequency and magnitude of conflicts between OromoSomali groups through time due to obligatory movement of conflicting groups in and around other localities and the actions against the contending groups aggravates tensions and violent conflicts in the area. This finding agrees with Emmanel et al., [1] in that the shift from rangelands into bush/shrub lands as the result of drought, aridity, and rangeland degradation has increased over time due to environmental degradation.

Besides, Abdikadir [30] noted that the rangelands have changed into bare termite mount the general indicator is encroachment of unpalatable bushes. On the contrary, although diverse ecological systems produce appropriate environment for pastoralists to manage risk through spatial dispersion of their herd [31], conflict impairs pastoral mobility and access to different grazing patches. Conflicting land use between agro-pastoralists (Oromo) and pastoralists (Somali) was found the third most important feature manifesting recurrence of violent conflicts in the area, significant at $p<0.01$. Change in land use implies change in property rights, as some cultivate while others need it only for grazing. This is one important factor explaining the conflict between Oromo and Somali groups in Mi'esso/Mullu area.

As usual, the Oromo groups till land while livestock still remained the basic source of livelihood. On the other hand, crop farming has become a source of conflict as Somali groups have never been involved in crop farming and increasingly 
resisted expansion of cultivation. One mechanism of resistance to land use change was to organize attacks during planting and harvesting seasons [31]. This has been designed to secure extensive communal grazing land. This factor of violent conflicts in Mi'esso/Mullu area has created the fourth ranked feature, the existence of historically hostile relationships between Oromo and Somali communities, significant at $\mathrm{p}<0.05$. The fifth ranked feature that characterized the conflict groups to engage in violent conflicts is increased frequency and magnitude of Oromo-Somali inter-group conflicts due to severe competition over meager rangeland resources (water and grazing), significant at $p<0.01$. Earlier study by Fekadu [11] has also reported that the Oromo-Somali ethnic intergroup conflicts have been driven by resource scarcity, poverty and historical animosities between members of the two groups.

Abdikadir [30] also indicated increasing rate of environmental degradation in PAP areas in eastern Ethiopia presented continuous instability that leads to tensions and conflicts among inter-group pastoral communities. Teshome [32] also stated that conflicts in PAP areas of eastern Ethiopia are frequent, complex, and occur at different levels. The region is well known for having volatile and hostile relationships between community groups due to numerous conflicts [33]. The volatile nature of regional boundary demarcation between Oromia and Somali regional states features the sixth ranked indicator for the manifestation for conflict environment around the loosely defined boundaries that caused skepticism among contending groups, significant at $\mathrm{p}<0.01$.

As usual, a community group suspects the opposing group for an attempt to take some actions around the disputable border areas which are considered as a means of ensuring 'legitimate' ownership rights. Sometimes contending parties use promotion and practicing illegal resettlements on contested areas to create tensions and conflicts in the community that lead to escalation of conflicts [34]. As large boundary areas between the two regional states remained formally unassigned to any group region. Most discussants of focused groups and KII also confirmed, a land area is traditionally belonged to a particular ethnic group and hence those community members inhabited earlier claim it by establishing ideal and physical boundaries; and as usual conflicts arise or erupt between the indigenous and late settlers who currently own the land.

More actors involvement in conflicts beyond local community is ranked seventh among the major features of Oromo-Somali inter-group conflict environment, mean score of 4.39 , significant at $p<0.05$. The findings revealed that since a few years the Oromo-Somali inter-group conflicts involved more actors including armed forces, local militias and Special Forces of Oromia and Somali regional states [16]. On the other hand, extended hands of the so-called conflict spoilers also aggravated conflicts in the area. These groups or individuals actively seek to hinder, delay or undermine conflict settlement [35]. They often benefit from the war system, and would be negatively affected by an end to conflict. In this category, groups included were those involve in free movement of weapons proliferation, and who smuggle contraband including electronics, textile, consumer goods, and firearms; while illegally send out live animals.

This indicator variable was found the eighth ranked feature manifesting presence of inter-ethnic tension and conflicts in the study area, significant at $\mathrm{p}<0.01$ ). Furthermore, massive internal displacement of households, women, children and aged people was also found the ninth importance feature of tensions and conflicts between agro-pastoral and pastoral inter-ethnic groups in Miesso/Mullu area. The federal DRM commission [36] reported that shifting trends were observed in Oromo-Somali inter-group conflicts following the 2018 violent armed conflicts that resulted in massive internal displacement of Oromo community members from Somali regional state.

Likewise, recent study by Gezu [29] also revealed hidden hands of power elites from the two groups were wagging proxy conflicts in Miesso/Mullu area and beyond during the same period in point. In effect, ten thousands of the Oromo agro-pastoral households in Miesso district were displaced from nine kebeles and resettled in neighboring kebeles [2]. Besides, Mehari [37] reports that the principal causes of internal displacement in Ethiopia are human induced conflicts and drought.

The last and tenth ranked feature was increased weakening of customary institutional sanction for crime (s) committed, mean score of $3.67 \mathrm{~m}$ significant at $\mathrm{p}<0.05$. The results of analysis showed and participants of FGDs and KII opined that the nature of ethnic based conflicts significantly weakened the capacity of customary institutions due to the fact that informal constraints (norms and self-imposed codes of conduct) have failed to serve and enforce to end or prevent conflicts between two ethnic groups with distinct social and cultural norms.

Difference in users' attributes does not open much room for bargaining and negotiation to lead to stable rules of resource use. However, traditionally customary institutions can improve access to range resources for various user groups when there are diverse resources across space and time. This is because diverse ecological systems produce appropriate environment for (agro) pastoralists to manage risk through spatial dispersion of herd [31].

\subsubsection{Frequency of Prevalence of Oromo-Somali Inter-group Conflicts}

In this sub-sub section the frequency of prevalence of Oromo-Somali inter-group conflicts in the past two decades (2000-2020) was assessed on five point scale and summery of the findings is presented in figure 4 below. Accordingly, quite majority of sample respondent households, 39\% reacted to inter-group conflicts prevail more than twice every year during the last two decades period of analysis; while $29 \%$ of sample households perceived that it has occurred twice every year during the same period of observation. Besides, $18 \%$ responded once every year, $10 \%$ observed that the occurrence varies from year to year and only $4 \%$ responded rarely occurrence of violent conflicts in the study area. 


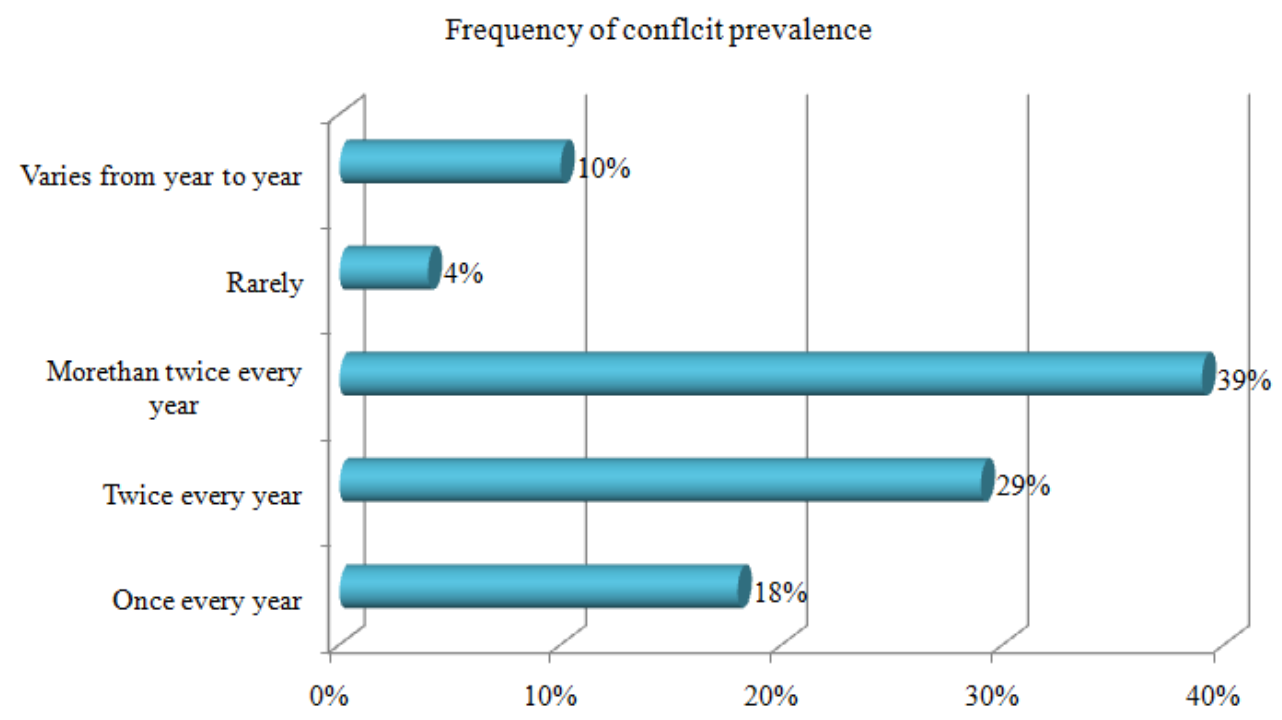

Figure 4. Frequency of prevalence of violent conflicts (Source: Own survey, 2021).

Overall, the results of this study implied that inter-group violent conflicts between Oromo and Somali groups were having frequent recurrence. The result of finding is in conformity with Bamlak [10] who found frequent prevalence of violent conflicts between contending groups in Mi'esso/Mullu districts area.

\subsubsection{Trends of Oromo-Somali Inter-group Conflicts}

The trend of Oromo-Somali inter-group violent conflicts was investigated and the results of analysis are illustrated in figure 5 below.

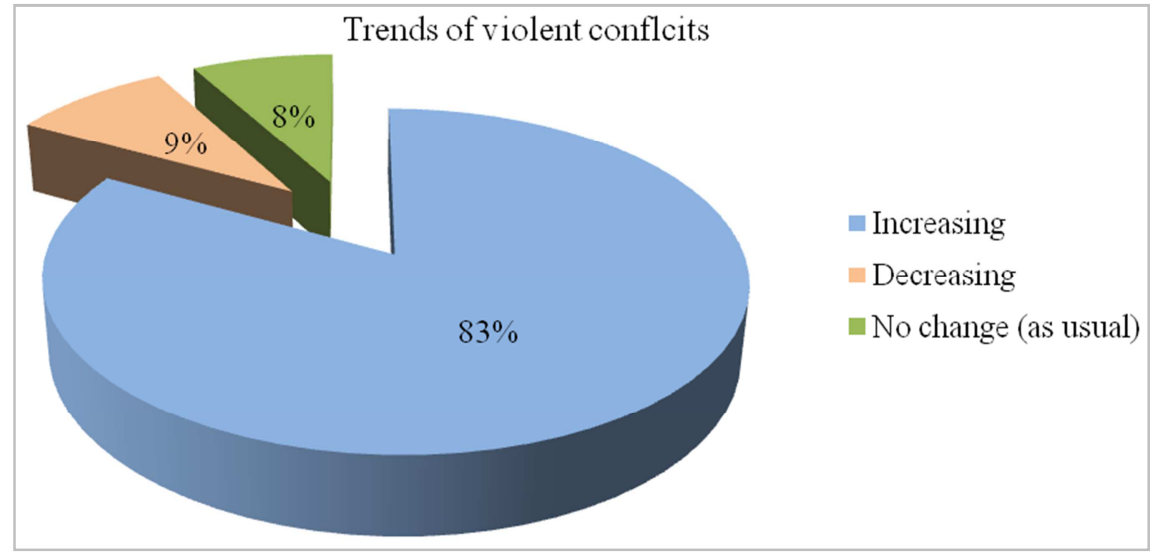

Figure 5. Trends of violent conflicts (Source: Own survey, 2021).

As can be observed from the figure, $83 \%$ of sample households perceived that violent conflicts have showed increasing trend in the past 20 years (2000-2020); while $9 \%$ reacted to decreasing trend and $8 \%$ responded unchanged trend was seen. Participants of FGDs and KIIs confirmed unanimously increasing trends have seen since the last two decades. They perceived the reason for increasing trend of violent conflicts in the study area is scarcity of range resources (grazing and water) and the stiff competition over the meager resource often affected by recurrent droughts coupled by other factors of range resources degradation and changes in land use [7]. As a result (agro) pastoral groups compete to maximize their share of the limited grazing resources and water points; the struggle inevitably leads to violent conflict.

\subsection{Main Causes of Oromo-Somali Inter-group Conflicts}

Mancosu et al. [3] observed that there are no specific causes of conflict, because it arises for different reasons and there are different types of conflicts in human society. Hence, the causes of conflict are numerous and complex, thus creating problem of analysis of specific conflict situations. In this study, sample respondents were asked to react to indicator variables for the causes of Oromo-Somali intergroup conflicts on five-point scale as, "5" very important, "4" important, "3" not sure, "2" less important and " 1 " not important from a list of items carefully constructed based on experiences of PAP households in Miesso/Mullu area and related literature. 
The study focused on the violent conflicts erupted between the two groups in the past five years (2015-2020). In effect, majority of the respondents tended to reflect attitudes towards eleven indicator variables (table 3). The result of Chi-square test statistics showed significance difference between the Oromo (agro-pastoralist) and Somali (pastoralist) groups, at $\mathrm{p}<0.01,0.05$ and 0.1 . This implies that the two PAP groups are significantly different in all factors that prompt contending groups to embark on conflicts due to their differences in socio-economic, cultural, political and resource-related factors.

The index values were calculated to rank the perceptions by weighing each group's perception (within and between the groups) and ordered according to their importance. As the findings revealed the first ranked response variable for the cause of inter-group conflicts between Oromo and Somali communities is severe competition over scarce range resources (grazing land and water), significant at $\mathrm{p}<0.01$, which it ranked second for the Oromo and first for Somali groups. This is due to the effects of climate change that resulted in recurrence drought and resources degradation as the results of population pressure and shrinkage of range patches for crop cultivation, as t participants of FGDs and KII interacted. Bamlak [10] also reported conflicts due to resource competition created one of the greatest insecurity challenges to the PAP production systems of Oromo, Somali and Afar groups in the eastern Ethiopia.

Table 3. Main causes of Oromo-Somali intergroup conflicts $(N=160)$.

\begin{tabular}{|c|c|c|c|c|c|c|c|c|}
\hline \multirow{2}{*}{ No. } & \multirow{2}{*}{ Description of the causes of conflict } & \multicolumn{2}{|c|}{ Agro-pastoralists } & \multicolumn{2}{|c|}{ Pastoralists } & \multicolumn{2}{|l|}{ Total } & \multirow{2}{*}{$\chi^{2}$ Test (sign.) } \\
\hline & & Index & Rank & Index & Rank & Index & Rank & \\
\hline 1. & Scarcity of grazing and water resources; & 4.43 & 2 & 4.59 & 1 & 8.92 & 1 & $43.5 * * *$ \\
\hline 2. & Livestock raiding; & 4.48 & 1 & 3.19 & 7 & 7.67 & 5 & $87.4 * *$ \\
\hline 3. & Lack of clearly defined regional boundary; & 4.23 & 8 & 2.65 & 9 & 6.88 & 9 & $67.8 * *$ \\
\hline 4. & Lack of property rights; & 3.63 & 10 & 4.32 & 2 & 7.95 & 2 & $74.1 * * *$ \\
\hline 5. & Revenge attack; & 3.86 & 9 & 3.73 & 4 & 7.59 & 6 & $84.8 * *$ \\
\hline 6. & Hate speech and provocative (hostile relationships); & 4.24 & 7 & 3.54 & 5 & 7.78 & 4 & $68.0^{*}$ \\
\hline 8. & Free movement and proliferation weapons; & 4.35 & 4 & 2.12 & 11 & 6.47 & 10 & $46.8 * * *$ \\
\hline 9. & Weak capacity of customary institutions; & 4.29 & 6 & 2.72 & 8 & 7.01 & 8 & $60.6 * * *$ \\
\hline 10. & Unfair resources (projects) distribution; & 3.06 & 11 & 4.04 & 3 & 7.10 & 7 & $48.2 *$ \\
\hline 11. & Plunder of properties; & 4.31 & 5 & 2.18 & 10 & 6.49 & 11 & $38.4 * *$ \\
\hline
\end{tabular}

Source: Own survey, $2021 * * *$ and $* * *$ - Significant at $\mathrm{p}<0.01,0.05$ and 0.1 .

Ephraim (2014) also recognized that natural resource wealth might be seen as more unjustly distributed than other wealth. The second most important indicator variable for the causes of recurrent conflicts in the study area was found lack of property rights for communal grazing areas, significant at $\mathrm{p}<0.01$. It is the tenth and the second ranked response factor for Oromo and Somali groups, respectively. Change in land use implies change in property rights, as some cultivate while others need it only for grazing. This is one important factor explaining the inter-group conflicts between Oromo and Somali communities [11]. At present, the findings demonstrated that frequent attacks are resulting in reduced benefits for Oromo groups from communal grazing land.

Many Oromo group members have the fear that this may cause displacement from their settlement area in the longterm. As the resistance from Somali groups increased through time through restricting access to communal grazing area to discourage crop farming from the other end of the vast grazing land. Clan leaders of Oromo group started to negotiate for access to the land they once enjoyed as common property with Somali groups. Among those agro-pastoralists who combine cultivation and herding, the claim to presently contested grazing area is based on the fact that it has been common property. A change in land use by some users of common property, as income diversification strategy, has become a threat for others who wish to sustain pastoralism (Somalis) as a livelihood leading to distributional conflict growing to violence [8].
The continual instability to the common property rights of Oromo and Somali groups has created conflict environment for both ethnic groups [11]. Expansionary urge of conflicting parties was found the third important response variable for inter-group conflicts in the study area, significant at $p<0.05$. It is the third and sixth ranked causative factor for Oromo and Somali groups, in the mentioned order. Similarly, participants of FGD and KII showed both groups are opposing one another for their expansionary attitudes in border areas to incorporate grazing patches and water points which had been once communal resources in history. For instance, the Somali groups strongly oppose Oromo groups for predominantly sedentarized farmers/agro-pastoralists that they often encroach into Somalis' grazing areas for settlement and cultivation. These accusations/counter-accusations as well as claims/counter-claims over border areas and resources spots are disputable agendas for both ethnic groups.

Hate speech, provocative incitement and enmity stereotype between the two groups were ranked the fourth important response variable(s) instigating inter-group conflicts in the area, significant at $p<0.1$. It is ranked as the seventh and fifth important cause of recurrent conflicts for Oromo and Somali groups, respectively. Participants of FGD and KII also unanimously opined that conflicts often break out with occasional clashes between members of community groups in the markets or at road junctions and grow to ethnic conflicts that result in instability and loss of life and devastations of resources. 
Lubo [38] observed that such type of disagreement or conflicts are the result of hostility between two or more groups. Besides, Markakis [39] support the idea that many ethnic hostilities in the Horn Africa have occurred because of the scarcity of resources and ethnic entitlements of resources after the 1991 Ethiopian ethnic-based regionalization policy. Livestock raiding was found the fifth ranked response variable for prompting contending parties into violent conflicts in the study area, significant at $p<0.05$. It is the first and seventh ranked causative factor for Oromo and Somali groups, in mentioned order.

Traditionally, livestock raiding has been organized on the bases of economic reasons, involving accumulation of wealth by one group at the cost of impoverishing the other. This is intended to establish marriage and livelihood for the rustling party. As there is retribution, it is a practice expected to be reciprocal among different resource users. However, the result findings revealed livestock raiding produces a threat to the weak actor in using communal grazing land. There is a direct link between fear of raids and avoidance of the grazing area. The gradual increase in the scale and severity of conflict is partly associated with the ever-worsening livestock raiding.

The Somali groups benefit more from raids differently in that the robbed animals can be instantly sold at local market or are trekked for informal export to neighboring Djibouti. Moreover, informal export arrangement ahead of raiding is another reason for engagement in raids, which shows the trans-boundary flow of benefits from raids. Meanwhile, such arrangement helps as a means to escape from the repossessing efforts of Oromo groups [8]. The findings also showed revenge attack, unfair distribution of resource, weak capacity of customary institutions, lack of clearly defined administrative boundary, free movement of firearms and proliferation of weapons and, plunder of properties (such as, schools, health centers, household assets, office furniture, crops, etc...) were found the causative variables to intergroup conflicts between Oromo and Somali community members in order of importance.

The rank orders covered from fifth to eleventh with significant differences between the study groups at $\mathrm{p}<0.01$, 0.05 and 0.1 . For instance, revenge attack for past harms, the sixth ranked response variable for prompting contending groups towards violent conflicts.

Participants of FGD and KII also agreed that as Miesso/Mullu area is volatile and lacks stability due to; first economic shocks (recurrent drought, lack of income, rise in market price, etc.) and second fragile security due to involvement of many actors in the markets (Miesso, Bikke, Mullu, Asebot, Bordodde) from various directions for economic reasons (including those contrabands). These cases oftentimes trigger and instigate members of contending parties and victims of past attack come across in the markets. Hence revenge attack is more likely to break out even with disagreement between two individuals. Brinkman, H., and Hendrix C. S., [40] also argue economic shocks are strongly correlated with civil conflict.
Economic shocks redistribute incomes and political power can create incentives for rebellion, while reducing the capacity of governments to repress or accommodate potential challengers. Besides, in situations where weak tradition of punishment and fair compensation as well as lack of procedures of conflict healing is overwhelming, the possibility of revenge attack is quite high. Besides, hostile and enmity relationships between conflicting group's simple cases of injury or attack of few individuals lead to severe conflicts with destructive consequences.

Plundering of properties of individuals and public institutions often occurred following severe conflicts spontaneously erupted in the markets or whenever triggered by public uprising or demonstrations or related to overt measures taken to halt traffic along the main highway road in the remote areas of Metahara and Awash. This was found the eleventh ranked indicator variable to cause inter-group conflicts in the Miesso/Mullu districts.

Collier [41] argues that the materialistic conception underlines decisive factors in all conflicts are economic motives. Lack of opportunities to external economic resources, low level of income and inadequate resources can be sources of conflicts.

Unfair distribution of resources was ranked the seventh response factor to cause conflicts. Accordingly, Miesso and Mullu districts have accessibility to infrastructure and located along Addis Ababa-Harar highway and railway lines. Hence, Miesso town has been serving as Ethio-Djibouti railway station and one of the biggest livestock (cattle, camel and goats) markets in eastern Ethiopia. Moreover, the federal government has recently launched the construction of Miesso dry port, one of the four dry ports in Ethiopia which is envisaged to serve as hub of eastern Africa trade corridor [9]. As a result there has been high flow of investment and development projects by the government and private investors. Besides, high movement of people from different direction is common phenomena during market days. As a result, unfair resources (projects) distribution is vividly seen compared to remote PAP areas beyond Miesso town and vicinity where lack of infrastructure and social services are poorly accessible.

In effect, movement of large number of PAP groups has borne disputes on resource competition, marketing and settlement areas and expansionary urge that oftentimes cause violent conflicts. UNOCHA [2] noted that inter-regional people's movement creates fear and suspicion among the different ethnic groups. However, not all development interventions are considered as causes of conflicts. Nonetheless, those development interventions which are not conflict sensitive may trigger existing or new conflicts. Conflict sensitivity is the ability of an organization to: 1) understand the context it operates in; 2) understand the interaction between its intervention and that context; and 3) act on this understanding to minimize negative impacts and maximize positive impacts on conflict [1]. On the other hand, weak capacity of customary institutions was found the eighth ranked response variable to prompt contending groups 
towards inter-group conflicts in the study area.

True, the findings revealed that as communities and individuals can succeed to expand their natural resource base or not depend on the ability of society (strength or weakness of the institutional environment) in defining and enforcing property rights, and in limiting opportunistic expansionary moves. In a society where the formal constraints (rules, laws and constitutions) and informal constraints (norms, conventions and self-imposed codes of conduct) are weak to define and enforce property rights and limit opportunistic behaviours, communities can find expansion beyond their historical territories as an alternative solution to the resource challenges, specifically in cases where absence of clearly defined regional boundary exists on the ground (the ninth ranked indicator variable for causes of inter-group conflicts). In an attempt to do so, communities can enter into conflicts and tensions.

Particularly, the situation is likely lead to conflict if the institutions (formal and informal) are not strong in mitigating and resolving conflicts. Miftah [42] argued that in the PAP areas of eastern Ethiopia, the key reason for conflict of interest to develop into violence is the gradual erosion of elders' authority and the state failure to provide security. Violent forms of conflict may need a different institutional arrangement and political intervention compared to disputes. Furthermore, the findings revealed free movement and proliferation of weapons was found one of the main causes of conflict by prompting contending groups to enter into violent conflicts (the tenth ranked indicator variable for causes of inter-group conflicts).

Hence the proliferation of weapons can contribute to conflicts, although the root causes of conflicts remain to be resource-based disputes [14]. Moreover, easily accessibility of fire arms, commercialization of cattle raiding and political incitement also instigate conflicting groups towards violent attacks [43]. Participants of FGDs and KIIs, Abba Gadas, Ugazes and clan leaders also stressed the importance of the above mentioned response factors to instigate contending parties towards severe conflicts in the study area.

\section{Summary and Conclusions}

\subsection{Summary}

This study aimed to investigate the causes and features of conflicts between Oromo and Somali PAP ethnic communities in Miesso district of West Hararghe Zone of Oromia and Mullu district of Sitti Zone of Somali Regional States, Ethiopia. Hence, based on the results of exploratory field survey and discussions with key informants conducted prior to the study period, 160 PAP households were randomly selected from six kebeles to facilitate primary data collection by using household survey. Qualitative data were also collected from local leaders, local elders, clan leaders ( $A b b a$ Gadas and Ugazes), religious heads, and community representatives of women and youth, PADAs, heads and experts of district level government offices and internally displaced peoples (IDPs) with the benefit of Key informants and Focus group discussion (FGDs) guided by carefully constructed checklists.

Field observation, informal discussion and review of secondary data were also supported data collection process of the study. Descriptive research design was used in this study accompanied by mixed qualitative and quantitative research approach and both quantitative and qualitative data were collected concurrently by using combinations of methods for data collection and data analysis so as to confirm, triangulate and substantiate the findings of the study. Both descriptive and inferential statistics were employed with appropriate statistical tests and interpretation of results was made accordingly. The findings of the study on the biophysical and socio-economic characteristics revealed that from the total 160 PAP households randomly selected for this study, the proportion of sample households from Oromo and Somali ethnic groups constituted $49 \%$ and $51 \%$, respectively.

The findings also demonstrated indicator variables to portray main features of Oromo-Somali inter-group conflicts in Miesso/Mullu area. As a result the perceptions of majority of sample households tended towards ten factors in order of importance, significant at $\mathrm{p}<0.01,0.05$ and 0.1 , to manifest the prevalence and escalations of tensions and violent conflicts in the area.

The main features identified include recurrent drought, rangeland degradation due to bush encroachment, conflicting land use between agro-pastoralists (Oromo) and pastoralists (Somali) contending groups, historically deviated hostile relationships reflected by day to day hate speech, enmity stereotype and incitement, instability due to increasing frequency and magnitude of violent conflicts, because of more actors involvement beyond local community members as a result of which internal displacement is common phenomenon, unregulated movement of firearms and weapons proliferation and eroded capacity of customary institutions. The findings also revealed the frequency of prevalence of inter-group violent conflicts between Oromo and Somali PAP parties in the past two decades (2000-2020).

As a result, $39 \%$ of sample households reacted to tensions and inter-group conflicts prevail more than twice every year, during the last two decades period of analysis; while $29 \%$ perceived twice every year, and $18 \%$ once every year, $10 \%$ observed that the occurrence varies from year to year and only $4 \%$ responded it occurred rarely. The results of analysis and the findings showed that tensions and inter-group conflicts between Oromo and Somali parties were having frequent phenomena in the study area with increasing trend over the same period of analysis, $83 \%$ of sample households confirmed. Furthermore, the findings of this study also exhibited the causes of inter-group conflicts between Oromo and Somali PAP communities in the study area.

Accordingly, 11 (eleven) response variables were ranked in order of importance. These include, scarcity of grazing and water resources, lack of property rights, expansionary urge, hate speech and provocative incitement, livestock raiding, revenge attack, unfair resources distribution, weak capacity 
of customary institutions, lack of clearly defined regional boundary, free movement and proliferation weapons and plunder of properties from private households or public institutions. However, significant differences were observed between the responses of the two contending study groups at $\mathrm{p}<0.01,0.05$ and 0.1 , in each of the indicator variables for the causes of inter-group violent conflicts in the Mi'esso/Mullu PAP area.

\subsection{Conclusions}

The conclusions were drawn from the key findings based on the objectives of the study. Inter-group conflicts between Oromo and Somali communities have long history in Miesso/Mullu PAP areas of eastern Ethiopia. Both Oromo and Somali clan/ethnic groups were inhabited in Miesso area before many years and still are the primary resource users of the area.

Although both groups had equal access to communal range resources since long time; antagonist attitudes grew following the shifts in conflicting land use system, the Oromo (clan) groups belonged to agro-pastoralist production system; whereas, the Somali (clan) groups were pastoralists and never engaged in crop cultivation. With the effects of population pressure and the stiff interest to crop cultivation in the range lands of Oromo groups created conflicts with Somali groups. At present, the recurring drought that had led to declining grazing and water resources base has gradually intensified competition and violent conflicts between the two groups. Besides, increased reduction in availability and quality of key rangeland resources due to bush encroachment and alien weed species significantly reduced access to range resources for both agro-pastoralist and pastoralist conflicting groups.

Lack of property rights for communal grazing lands is another factor for the cause of violent conflicts between the two PAP groups. Change in land use implies change in property rights, as some cultivate while others need it only for grazing. This is one important factor explaining the intergroup conflicts between Oromo and Somali communities. Weak capacity of government security institutions, lack of commitment to ensure rule of law aggravated competition and prompted contending parties into recurrent violent conflicts due to expansionary urge, hate speech and provocative incitement, livestock raiding and revenge attack for past harm. Besides, free movement and proliferation of weapons and plunder of properties from private households or public institutions would have been resolved if the government system properly functions in the PAP areas of eastern Ethiopia.

Moreover, unfair resources distribution, lack of defined regional boundary and eroded capacity of customary institutions were all found to be the causal factors of tensions and violent conflicts. The conflict context in Miesso/Mullu area is characterized by recurring prevalence of tensions and violent conflicts that result in significant socio-economic losses that jeopardized the life and livelihood of PAP communities.

\subsection{Recommendations}

Resource scarcity based violent conflicts between PAP groups have severe impacts on society, economy, and environment at different levels. This demonstrates that deliberately designed interventions are necessary to help reduce vulnerability and concurrently with mitigating the impacts to sustainably improve access to communal resources. Based on the findings of this study the following suggested recommendations were made.

1) Emphasis on promotion of peaceful dialogues to strengthen cooperation and promote mutuality in improving access to scarce resources.

2) Strengthening development interventions to improve access to scarce range resources of grazing land and water points.

3) Empowerment of the local, districts and zonal level public institutions to bear duties and discharge expected responsibilities.

4) Existing ethnic based federalism in Ethiopia restricts easy movement of pastoralists across regions and even trans-national boundaries in search of pasture and water. There should be recognition to the flexibility/mobile nature of pastoral way of life during drought seasons irrespective of manmade regional boundaries.

5) If not possible, there should be another alternative solution to the degrading and deteriorating resource environment which jeopardized the PAP livelihood system under pressure.

6) Development of infrastructures like water points (water resources development), education and health services, improving access to road, promotion of irrigation agriculture, etc are urgently and strongly required.

7) It is also important to consider mapping of mobility patterns of (agro) pastoralists in each of PAP areas and rangelands to better manage and improve access to mobility during drought periods.

\section{References}

[1] Emmanel M. Falanta and Kenneth M. K. Bengers, 2018. Drivers and Consequences of recurrent Conflicts between Farmers and Pastoralists in Kilosa and Mvomero District, Tanzania. Journal of Sustainable Development (JSD), Vol. 11, No. 4, Canadian Centre of Science and Education.

[2] UNOCHA, 2018. Ethiopia: Conflict Displacement Situation Report. For Public Circulation, January, 2018. Addis Ababa, Ethiopia.

[3] Mancosu, N., Snyder, R. L., Kyriakakis, G., and Spano, D. (2015). Water Scarcity and Future Challenges for Food Production. Water, 7 (3), 975-992. https://doi.org/10.3390/w7030975.

[4] Asebe, R. 2016. Competing Orders and Conflicts at the Margins of the State: Inter-group Conflicts along the EthiopiaKenya Border. African Journal on Conflict Resolution, Vol. 16, No. 2, pp. 182-201. 
[5] Marco, B. 2010. The politics of Space in Borana Oromo, Ethiopia: Demographics, Election, Identity and Customary Institutions. Journal of Eastern African Studies (JEAS), Vol. 4 No. 2, pp. 221-246.

[6] Esayas, N., Solomon D., Girma, K. 2019. Pastoral Development in Ethiopia: Trends and the Way Forward. International Bank for Reconstruction and Development/the World Bank, 1818.

[7] Zigale T., 2016a. Constraints of Pastoral and Agro-pastoral Livelihood Diversification in Eastern Ethiopia: The Case of Mieso District, Oromia Regional State. International Journal of Sciences: Basic and Applied Research (IJSBAR), Vol. 26, No 3, pp. 267-274.

[8] Fekadu Beyene, Boku Tache, Gadissa Tesfaye, Jabessa Teshome, and Medihanit Adamu, 2016. Assessment of Customary land Administration and Natural Resource Management in Pastoral Areas of Oromia Regional State. Tetra for the United States Agency for International Development (USAID), Addis Ababa, Ethiopia.

[9] Jeylan, W. 2016. Taking Narratives on Identity-Based Conflicts in the Horn of Africa Seriously: The Case of Intergroup Conflicts at Pastoral Frontiers in Ethiopia. International Journal of Peace Studies, Vol. 21, No. 1. pp. 145-165.

[10] Bamlaku Tadesse, Fekadu Beyene, Workneh Kassa and Richard Wentzell., 2015. The Dynamics of (Agro) Pastoral Conflicts in Eastern Ethiopia. Ethiopian Journal of OSSAH Vol. XI, No. 1. 37-81. Addis Abeba Ethiopia.

[11] Fekadu, G. 2013. The Sources of Ethnic Strives and Tensions among the Issa-- Somali and Ittu-Oromo Pastoral Communities of Eastern Ethiopia. Technical Report, ResearchGate, pp. 1-23.

[12] Zigale, T. 2016b. Indigenous Institutions as an Alternative Conflict Resolution Mechanism in Eastern Ethiopia: The Case of the Ittu Oromo and Issa Somali Clans. African Journal on Conflict Resolution, African Centre for the Constructive Resolution of Disputes (ACCORD), Durban, South Africa, Vol. 16, No. 2, pp. 85-110.

[13] WHZASO (West Hararghe Zone Adiministration and Security Office), 2019. Historical Trend Analysis of Conflicts between Pastoral and Agro-pastoral Communities in West Hararghe Zone (1971-2019), Chiro, Ethiopia.

[14] ECA. 2017. 'New Fringe Pastoralism: Conflict and Insecurity and Development in the Horn of Africa and the Sahel'. Economic Commission for Africa (ECA), Addis Ababa, Ethiopia.

[15] UNEP, 2011 (United Nations Environmental Programme). Livelihood Security: Climate Change, Migration and Conflict in the Sahel. Geneva: UNEP.

[16] Abduselam, A. 2018. Assessment of Conflict Dynamics in Somali National Regional State of Ethiopia. Journal of public Policy and Adminstration, Vol. 2, No. 4, pp. 40-48.

[17] WHZPEDO (West Hararghe Zone Economic Development Planning Office), 2018. West Hararghe Planning and Develoment Office Final Annual Report. West Hararghe Zone Planning and Development Office, Chiro, Ethiopia.

[18] IPMS (Improving productivity and marketing success of Ethiopian farmers), 2007. Mi'esso Pilot Learning Site diagnosis and program design. Addis Abeba, Ethiopia.
[19] Ayana A. and Fekadu B., 2003. Current range conditions in southern Ethiopia in relation to traditional management strategies: The perception of Borana pastoralists. Tropical Grasslands, 37: 53-59.

[20] MWDEDPO, (Miesso Woreda Planning and Economic Development Office), 2020. Historical Trend Analysis of Conflicts between Pastoral and Agro-pastoral Communities in Miesso Woreda (1971-2020), Chiro, Ethiopia.

[21] John Adams, Hafiz T. A. Khan, Robert Raeside and David White, 2007. Research Methods for Graduate Business and Social Science Students. California, Sage.

[22] Cohen L., Manion L. and Morrison K. 2007; Research Methods in Education, 6 Edition, USA, Routl Creation, Discussion paper: German Development Institute.

[23] Kothari, C. 2004. Research Methodology: Methods and Techniques. $2^{\text {nd }}$ Edition, New Delhi: Wisley Eastern, New Age International (P) Ltd., Publishers, India.

[24] Creswell, J. W. 2013. Qualitative Inquiry and Research Design: Choosing among Five Approaches. $3^{\text {rd }}$ Edition, Los Angeles: Sage, USA.

[25] James P. Sampson, J., 2017. A Guide to Quantitative and Qualitative Dissertation Research, $2^{\text {nd }}$ Edition. College of Education, Florida State University, USA.

[26] Amin, A. 2005. Social Science Research, Conception, Methodology and Analysis. Kampala: Makerere University Printery.

[27] Kumar, R. 2005. Research Methodology: A Step-By-Step Guide for Beginners. Pearson Education, Australia.

[28] Miller, C. E. and King, M. E. 2005. A Glossary of Terms and Concepts in Peace and Conflict Studies. $2^{\text {nd }}$ Edition, University for Peace, Geneva, Switzerland.

[29] Gezu, G. 2018. Assessment of Factors Affecting Interregional Conflict Resolution in Federal Ethiopia: The Case of Oromia and Somali Regions. MA Thesis, College of Law and Governance studies, Addis Ababa University, Ethiopia.

[30] Abdikadir, A. 2015. The Impact of Conflicts in the Horn of Africa: a case study of Kenya. MA Thesis, Institute of Diplomacy and International Studies, University of Nairobi, Kenya.

[31] Ahmed, S. 2005. Conflict is Everyday Business, Changing Nature of Local Conflict in Federal Republic of Ethiopia: The Case Study in Mieso District. Institute of Development Studies, University of Sussex, Brighton.

[32] Teshome, M. 2010. Cross-Border Pastoral Conflict: the case of Dassenetch and Nyangatom in Southern Ethiopia. Journal of Anthology of Peace and Security, Institiute of Peace and Security Studies in Collaboration with Friedrich Ebert Stiftung, Addis Ababa University, Ethiopia, pp. 174-214.

[33] Muhabie, M. 2015. Ethnic Federalism: A Means for Managing or a Triggering Factor for Ethnic Conflicts in Ethiopia. Journal of Social Sciences, Vol. 4, No. 4, pp. 94-105.

[34] Kinfe S., 2014. Dispute Resolution Mechanisms among the Afar People of Ethiopia and Their Contribution to the Development Process. J. Tran-disciplinary Res. Southern Africa. 10 (3): 152-64.

[35] Newman, E. and Richmond, O., 2006. Peace building and spoilers. Conflict Security and Development, 6 (1), 101-10. 
[36] Federal Democratic Republic of Ethiopia Ministry of Peace (FDREMP), 2019. Final Social Assessment Report for Lowland Livelihood Resilience Project (LLRP), Ministry of Peace, Addis Ababa, Ethiopia.

[37] Mehari T. 2017. Causes, Dynamics and Consequences of Internal Displacement in Ethiopia. Working Paper Division: Global Issues Stiftung Wissenschaft und Politik (SWP), Institute for International and Security Affairs, D-10719 Berlin, Germany.

[38] Lubo, T. 2013. The post 1991 Inter-ethnic Conflicts in Ethiopia: An Investigation. International Journal of law and Conflict Resolution, Vol. 1, No. 1, pp. 108-115.

[39] Markakis, J. 1998. Resource Conflict in the Horn of Africa (London: Sage Publications). In: his (1987) National and Class Conflict in the Horn of Africa. (Cambridge: Cambridge University Press). See also Edmond J. Keller (1981), "Ethiopia: Revolution, Class, and the National Question," African Affairs, Vol. 80, No. 321, pp. 519-549.
[40] Brinkman, H., \& Hendrix, C. S., 2011. 'Food Insecurity and Violent Conflict: Causes, Consequences, and Addressing the Challenges. Challenges, (July), 1-28. Retrieved from http://documents.wfp.org/stellent/groups/public/documents/ne wsroom/wfp238358.pdf

[41] Collier, P. 2000. Doing Well Out of War in Greed and Grievance: Economic Agendas in Civil Wars In: Mats Berdal and David Malone (eds.), Boulder, CO: Lynne Rienner.

[42] Miftah, A. 2014. Effect of Climate Change on Pastoralism in Ethiopia: The case of Awash. MA Thesis, Addis Ababa University, Addis Ababa, Ethiopia.

[43] Cheserek G, J, Omondi P, and Odenyo V. 2012. Nature and Causes of Cattle Rustling among some Pastoral Communities in Kenya. Journal of Emerging Trends in Economics and Management Sciences (JETEMS) 3 (2): pp. 173-179. 